\title{
Design, time and empire: Charles Darwin's paradigm shift
}

\begin{abstract}
The development of Charles Darwin's idea of natural selection is analyzed in this article using Thomas Kuhn's concept of a paradigm shift. Kuhn's insights point to the crucial question of what brings about scientific development. Science is understood as a social activity and scientific theories are interpreted as intellectual constructions somehow imposed on data, not demanded by it. In this sense, all the evidence assembled by Darwin in his On the origin of species that ranges from the discussion of selective breeding to biogeography to systematics to paleontology to anatomy to embryology, is not as important for explaining how his work anticipates the foundations of a revolution in biology, as the mental constructs that allowed Darwin to consider the possibility of a new paradigm. Science is not essentially motivated by empirical discoveries but by mental constructs. We will develop three of these constructs: design, time and empire, as being in some sense accountable for permitting Darwin to ponder on the possibility of a paradigm shift.
\end{abstract}

Keywords: paradigm shift, Kuhn's insights point, paleontology, revolution, history
Volume 4 Issue 4 - 2019

\section{Ana Sevilla}

Research Associate, Universidad San Francisco de Quito, Ecuador

Correspondence: : Ana Sevilla, Research Associate, Universidad San Francisco de Quito, Ecuador, Email anasevillaperez@gmail.com

Received: June 13,2019 | Published: July 17, 2019

\section{Introduction}

In the fourth edition of his On the origin of species, Charles Darwin adds a historical sketch where he describes the progress of opinion regarding the origin of species. He states that "the great majority of naturalists believed that species were immutable productions, and had been separately created" and that only a few naturalists "have believed that species undergo modification and that the existing forms of life are the descendants by true generation of preexisting forms". Darwin then identifies and discusses the scientists who had preceded him in articulating species variability. In this introduction Darwin provides a guide for the precursor historiography of his theory and the way he tells this story ends up building a creation vs. evolution model. A "forerunners of Darwin" story is then created and literature since then has been directed to formulating this model, the preoccupation with the predecessors of Darwin has never quite ended.

In this article we will argue that the development of the idea of natural selection is not necessarily an end result of Darwin's fieldwork (data). It has to do with a process more like the one defined by Thomas Kuhn ${ }^{1}$ who claims that science is a social activity and that theories are intellectual constructions somehow imposed on data, not demanded by it. Kuhn's insights point to the crucial question of what brings about scientific development. His thinking suggests that science is not necessarily moved by empirical discoveries but by mental constructs (metaphors, equivalences, creative leaps). Facts are so rooted in a paradigm that they just do not have the kind of neutral probative authority they were once thought to enjoy. If we follow Kuhn's insights, the quantity and diversity of evidence assembled by Darwin in his On the origin of species that ranges from the discussion of selective breeding to biogeography to systematic to paleontology to anatomy to embryology, is not as important for explaining how his work anticipates the foundations of a 'revolution' in biology, as the mental constructs that allowed Darwin to consider the possibility of a new 'paradigm', to use Kuhn's ambiguous and debated term.

\section{The problem of design}

On 17 December 1832, as part of his journey aboard the British survey ship H.M.S. Beagle, Charles Darwin arrived in Tierra del
Fuego at the southernmost tip of South America. ${ }^{2}$ This was one of the most important stops of the voyage, since Captain Robert Fitzroy was returning to their motherland three natives of the Yahgan tribe he had taken to England a few years back: a man named York Minster, a girl named Fuegia Basket and a boy named Jemmy Button. Fitzroy's hopes were to spread Christianity and European culture in these faraway lands. Darwin's impressions of this event are recorded on Chapter 10 of his Journal of researches onboard the Beagle. ${ }^{2}$ His narration alternates between the unpredictable ways of the native Fuegians, the beauty of the wilderness of Tierra del Fuego and his own thoughts on the broad disparities between human societies.

Like most Europeans of the day, Darwin considered the natives of Tierra del Fuego as savages. He described "the sight of a naked savage in his native land" as an "event which can never be forgotten". They were to him "like the troubled spirits of another world". ${ }^{3}$ "The Fuegians are in a more miserable state of barbarism, than I had expected ever to have seen a human being.- - In this inclement country, they are absolutely naked, $\&$ their temporary houses are like what children make in summer, with boughs of trees.- I do not think any spectacle can be more interesting, than the first sight of Man in his primitive wildness. - It is an interest, which cannot well be imagined, untill it is experienced"3 Darwin was staggered by the wide difference between savage and civilized men. He believed this difference to be greater than that between a wild and a domesticated animal.

Many years later, when writing the concluding remarks of $O n$ the origin of species Darwin would recall these crucial impressions. He turned them into a metaphor for understanding a potential transformation of the study of natural history. Darwin ${ }^{4}$ envisioned a time when we would "no longer look at an organic being as a savage looks at a ship". This statement brings us back to the cold and inhospitable shores of Patagonia. Impregnated in Darwin's youthful mind is his first encounter with the Fuegians. How to interpret their unfamiliar gestures as they witnessed the arrival of the European party? These savages, as Darwin conceived them, looked at the H.M.S. Beagle as something wholly beyond their comprehension. This absolute perplexity, this enormous distance towards what is known, familiar and conceivable; is how Darwin translated our 
understanding of organic beings. He continued his metaphor stating the possibility of regarding "every production of nature as one which has had a history". Darwin thus used his recollections of the outright otherness of the American savages as a starting point for defining his vision of how the study of natural sciences should be guided.

The absolute clash of paradigms he experienced on board the Beagle is thus turned into an invitation to think in a radically different way of what his intellectual circle was accustomed to. He called for the understanding of complexity in its simplicity: "When we contemplate every complex structure and instinct as the summing up of many contrivances, each useful to the possessor, nearly in the same way as when we look at any great mechanical invention as the summing up of the labour, the experience, the reason, and even the blunders of numerous workmen" ${ }^{\prime 4} \mathrm{He}$ finally anticipated, almost as a celebration, that "when we thus view each organic being, how far more interesting, I speak from experience, will the study of natural history become!"4 Darwin's particular insights on the study of natural history led him towards the formulation of an evolutionary theory that is based on chance variation and natural selection. Gould wonders if such a categorically mechanical view is partly a response to Captain Fitzroy's dogmatic defense of the argument of design. In fact, many other evolutionary theories that had been formulated during the nineteenth century were far more affable to Fitzroy's views of Christianity. The young British captain of the Beagle believed that the existence of God could be deduced from the perfection of the organic structures. This concept differed from a more materialistic view, that of Darwin, where variation and natural selection determined the perfection of the organic world. Gould speculates on the mixed feelings of those long nights during five years that Darwin sat at the Captain's table. He finally suggests that Fitzroy, or what his philosophical outlook represented, "may well have been far more important than finches, at least for inspiring the materialistic and atheistic tone of Darwin's philosophy and evolutionary theory"

What Gould's speculations help us see is the struggle of two paradigms that could have taken place on board the Beagle and inside Darwin's head. This paradigm shift would somehow move Darwin away from the wonder linked to the intellectual passivity of the savage looking at a ship and walk towards the understanding of complexity in its simplicity. What is important is that Darwin understood perfectly the idea of design that he later challenged. In fact, the arguments of natural theology had a substantial influence on his own early thinking about natural history: "I did not at that time trouble myself about Paley's premises; and taking these on trust, I was charmed and convinced by the long line of argumentation". ${ }^{6}$ Darwin is referring to the arguments of design whose most celebrated version belonged to the Anglican clergyman William Paley's (17431805) 1802 proposition of the analogy of the Watchmaker. In a letter to his dear friend and neighbor, the naturalist John Lubbock Darwin expressed his former admiration for Paley's Natural Theology: "I do not think I hardly ever admired a book more than Paley's Natural Theology: I could almost formerly have said it by heart". Darwin read Paley's works at Cambridge University and admired them deeply.

Paley's theological view of nature was still, by 1859, a strong explanation about the beauty and order of the world. It was also very familiar to Darwin's audiences. Paley's analogy compared the deduction of the existence of a human watchmaker from the discovery of a watch, with the logical conclusion of the existence of a Divine Creator as an inference from observation and reasoning on the order and beauty of nature. "But being once, as we have said, observed and understood, the inference we think is inevitable, that the watch must have had a maker - that there must have existed, at some time and at some place or other, an artificer or artificers who formed it for the purpose which we find it actually to answer, who comprehended its construction and designed its use"

In his Natural Theology Paley developed the concepts of perfect adaptation and divine design in nature. The analogy of the watchmaker is turned into an argument that could explain the intricate structures found in nature, such as the human eye. In fact, just like Paley, Darwin wrestled with the difficulty of the eye when he discusses the problem that organs of extreme perfection posed to the theory of natural selection. This is treated in chapter VI of On the Origin of Species entitled "Difficulties on theory". This chapter comes at the center of Darwin's work after the first five sections that present the theory of natural selection and describe the ambiguous and poorly understood laws of variation on which Darwin's argument of selection rests upon. Many implications of Darwin's theory for the religious context on which he wrote can be derived from this chapter. ${ }^{5}$ In this section of the book Darwin ${ }^{7}$ admits that there are "a crowd of difficulties" to his theory of natural selection and that "some of them are so grave that to this day (he) can never reflect on them without being staggered". One of these difficulties is the problem of organs of extreme perfection of which the eye is the example par excellence. By choosing the eye as a centerpiece of his explanation, Darwin was discussing with Paley's classic argument that saw the manifestation of a divine order in the world. Darwin introduces the problem of the eye in very dramatic terms bringing attention both to the incredible challenge of explanation and to the extreme perfection of the example: "To suppose that the eye, with all its inimitable contrivances for adjusting the focus to different distances, for admitting different amounts of light, and for correction of spherical and chromatic aberration, could have been formed by natural selection, seems, I freely confess, absurd in the highest possible degree". ${ }^{7}$

Yet, Darwin anticipates that if he could find numerous gradations between a perfect and complex eye and an imperfect and simple one, if theses gradations proved to be useful to its possessor under changing conditions of life, and finally if these variations are inherited; then "the difficulty of believing that a perfect and complex eye could be formed by natural selection, though insuperable to our imagination, can hardy be considered real". " "If it could be demonstrated that any complex organ existed, which could not possibly have been formed by numerous, successive, slight modifications, my theory would absolutely break down. But I can find out no such case" Any organ can be produced with small, transitional and successive changes. Darwin manifested his astonishment at the fact that it is extremely rare to find an organ "towards which no transitional grade is known to lead" Darwin linked the truth of this remark to the "old cannon in natural history of Natura non facit saltum". And then asked him why this would be on the theory of Creation. "All parts and organs of many independent beings, each supposed to have been separately created for its proper place in nature, are so invariably linked together by gradual steps? (...) Why should not nature have taken a leap from structure to structure?"?

Natural selection, can never take a leap. She must advance by the "shortest and slowest steps" In the discussion of the formation of the eye we can understand how Darwin's insights break the watchmaker's paradigm. While anti-evolutionists maintained that the eye would only work if it were complete in all its details, Darwin, on the other hand, argued that the eye had developed, becoming increasingly complex over a long period of time. For Darwin, the structure of the eye did not demand the assistance of a supernatural designer. It could 
have evolved gradually, with each stage bringing a real advantage - as Darwin's theory demanded.

\section{An interpretation of time as a paradigm}

A starting point for any attempt of understanding evolution as a paradigm is the achievement of a secularization of time as Johannes Fabian understands it. Two elements are of particular importance to realize such conception. First of all, time is imminent to, hence coextensive with, the world (or nature, or the universe, depending on the argument); and, second, relationships between parts of the world (in the widest sense of both natural and sociocultural entities) can be understood as temporal relations. The qualitative change from what Fabian calls medieval to modern time conceptions could not have been made without a breakthrough based essentially on a quantitative change that has to do with the publication of Charles Lyell's Principles of Geology in 1830. The impact of this British geologist on the genesis and development of Darwin's ideas on biological evolution is stated by Darwin himself in a passage titled "On the lapse of time" in On the origin of species: "He who can read Sir Charles Lyell's grand work on the Principles of Geology, which the future historian will recognize as having produced a revolution in the natural sciences, yet does not admit how incomprehensibly vast have been the past periods of time, may at once close this volume"

Lyell's contention was with uniformitarian's, a concept developed by the Scottish geologist James Hutton that was to account for the present shape of the world without recourse to unique, simultaneous creation or to repeated acts of divine intervention (catastrophes). His book was an attack on the common belief that unique catastrophes or supernatural events-- such as Noah's flood -shaped the surface of the Earth. According to this view, a once-tumultuous period of transformation had slowed to today's quieter pace. The French zoologist Georges Cuvier was a strong advocate of the theory of catastrophism. Drawing from his knowledge of dinosaur extinctions, he based his hypothesis on the assertion that there had been violent and sudden natural catastrophes that would explain the extinction of certain species, like dinosaurs, while still considering that species were fixed and did not change. According to Cuvier, organisms living in the area where a catastrophe had struck were frequently exterminated and would be supplanted by new life forms moving in from other geographic regions.

Although such catastrophic events may eventually occur, Lyell believed that there was more commonly an accumulation of progressive changes over long periods of geologic time. Lyell documented the fact that the earth must be extremely old and that throughout time the planet has continually undergone processes that changed and shaped the land, including erosion, earthquakes, glacial movements, volcanoes, and even the decomposition of dead plants and animals. The theory that resulted from Lyell's observations was eventually called uniformitarianism. Lyell applied and extended Hutton's concept into a formula for deciphering and interpreting the structure of historical events that have shaped the earth across geological time. Lyell argued that the formation of the Earth's crust took place through countless small changes occurring over vast periods of time, all according to known natural laws. His uniformitarian proposal was that the forces molding the planet today have operated continuously throughout its history.

Uniformitarian science interpreted the present as the key to the past. Darwin extended that principle to biology. He spoke of the "wonderful relationship (...) between the dead and the living" and how it will "throw more light on the appearance of organic beings on our earth, and their disappearance from it, than any other class of facts". ${ }^{8}$ Species, like geologic structures, evolved gradually or disappeared gradually. Like the shifting, rising and falling of land that Lyell described, Darwin held that the forces seen today in the biologic world (reproduction, inheritance and competition) progressively shaped the entire variety of life on Earth. These views are present in Darwin's thoughts very early on. In fact, the eight chapter of the Voyage of the Beagle is greatly concerned with the problem of the extinction of species and how previous paradigms are difficult to sustain, in the light of his observations. Darwin was deeply astonished by the "changed state of the American continent": "formerly it must have swarmed with great monsters: now we find mere pigmies, compared with the antecedent, allied races". He then cited Buffon's appreciations of the fauna of the continent and considered that if he "had known of the gigantic sloth and armadillo-like animals, and of the lost Pachydermata, he might have said with a greater semblance of truth that the creative force in America had lost its power, rather than that it had never possessed great vigour". Darwin reflected on what had possibly exterminated all these gigantic quadrupeds and flirted with the idea of catastrophism only to reject it later on: "The mind at first is irresistibly hurried into the belief of some great catastrophe; but thus to destroy animals, both large and small, in Southern Patagonia, in Brazil, on the Cordillera of Peru, in North America up to Behring's Straits, we must shake the entire framework of the globe". ${ }^{8}$

The problem of the extinction of the American horse was especially puzzling to Darwin. ${ }^{7}$ He described the whole subject as being involved in "the most gratuitous mystery". He said that no one can have marveled more than he did at the extinction of species when he found in La Plata (Patagonia) "the tooth of a horse embedded with the remains of Mastodon, Megatherium, Toxodon, and other extinct monsters": "I was filled with astonishment; for seeing that the horse, since its introduction by the Spaniards into South America, has run wild over the whole country and has increased in numbers at an unparalleled rate, I asked myself what could so recently have exterminated the former horse under conditions of life apparently so favourable". Darwin revisited his thesis on the relationship between the dead and the living and asked what can be said of the extinction of the American horse. Darwin witnessed the vitality of the population of introduced horses, he described that "thousands and hundreds of thousands of the descendants of the stock introduced by the Spaniards" overrun the Patagonian plains. And paradoxically, in those same plains a local population was exterminated. Did the plains fail of pasture? "Have the subsequently introduced species consumed the food of the great antecedent races?" Darwin concluded that there was no fact in the long history of the world so startling as the wide and repeated exterminations of its inhabitants.

Let us now return to Fabian's argument. He considers that the basis for nineteenth-century attempts to formulate specific theories of evolution is the secularization of time. By this category he understands that time becomes an intrinsic element of the world and that the relationships between parts of the world can be understood as temporal relations. We see both these elements in the connection that Darwin made between the living and the dead while discussing the extinction of species. As we have stated earlier, Fabian's secularization of time goes hand in hand with Lyell's geological time. This argument was not present in the different theories that, before Darwin's theory of natural selection, explained the way species, changed (Uniformitarianism, Catastrophism and Lamarckism). In fact, geological time opened the plausibility and a scope that eighteenth-century formulations of change in the natural world lacked. Furthermore, while it is true that the new concept afforded first of all an immense quantitative 
expansion of time, its actual significance was of a qualitative nature. As Fabian states, the difficulty with the estimations based on the Bible was not only that they did not comprise sufficient time for natural history: redoing the calculations and extending the chronology could have dealt with that sort of impediment. The bottom line reason why the biblical timeline had to be rejected was that it did not contain the appropriate kind of time. The problem was that it was calculated as the time after creation as imparted in the Scriptures. In this way, it revealed meaningful events, both mythical and historical, and as such it was chronicle as well as chronology.

The end result is that biblical time was linear rather than tabular, and did not allow for time to be a variable independent of the events it marked. This turned out to be an unsurpassable difficulty since such a meaningful time system could not become part of a Cartesian scheme of time-space coordinates, crucial for scientists to plot a crowd of ordinary records over neutral time. Time had to be naturalized; it needed to be separated from events meaningful to mankind: "Unlike old sacred time the new naturalized time was no longer the channel of an unbroken, meaningful story: it was a way to order a fundamentally irregular and disconnected geological and paleontological record"

This new concept contrasted with previous ideas on three accounts that produced substantial philosophical conflicts with its opposing visions. The first disparity was the immensity of naturalized time. In fact, the history of man occupied a trifling span on the vast scale of natural evolution. Secondly, those who defended biblical time could not come to terms with the bare futility of simple physical duration. The belief that time "accomplished" things was extremely resilient. And finally, the new concept of time clashed with the old concept by being merely an abstract methodological chronology; it did not mark steps leading to civilization.

While assessing the temporal dimension of natural selection, Darwin developed a profound awareness that time, once it was naturalized, could and should not be rehistorized (this is exactly what the social evolutionists would try to do, later on). In the following passage of On the origin of species, Darwin discards the temptation to read some sort of inner necessity or meaning into the temporal dimension of evolution:

"The mere lapse of time by itself does nothing either for or against natural selection, I state this because it has been erroneously asserted that the element of time is assumed by me to play an all- important part in natural selection, as if all species were necessarily undergoing slow modification from some innate law".?

\section{Darwin and empire}

The progress of science goes hand in hand with the expansion of Europe. The interactions between science and imperial expansion form an intricate part for the understanding of Darwin's mind and prospects. In fact, the sciences of collection and comparison - botany, zoology, anthropology and geology - all of which are crucial to Darwin's thinking process depended on European's exposure to the planet's physical and organic diversity and to the scientific traditions of non-European people. These disciplines could not make sense without the world as a whole. The Voyage of the Beagle is infused with Darwin's sense of the grandeur of nature. Darwin seems to be very aware of his western or European view of the world, since he is constantly making remarks on the way he feels when exposed to the absolute exuberance of tropical diversity. For example, when talking about beetle collections, one of his youthful passions, Darwin remarks that "the number of minute and obscurely colored beetles is exceedingly great" in the countryside surrounding Rio de Janeiro. The naturalist contracts this fact with the cabinets of Europe that only possess the larger species from tropical climates. This disparity between an exuberant nature and the cabinets of European collectors suffices to "disturb the composure of an entomologist's mind". It is a disquieting thought to imagine and "to look forward to the future dimensions of a complete catalogue". ${ }^{8}$

We find the same astonishment when he describes another observation in Rio de Janeiro. Darwin recalled that any person fond of natural history would enjoy walking in England: he would always find something that would catch his attention. But this fascinating encounter with the natural world takes on a completely different dimension in such fertile soils as the Brazilians. These novel ecosystems that are "teeming with life" offer such exhilarating experiences that the naturalist finds himself "scarcely able to walk at all". ${ }^{8}$ The mind of the European scientist is thus confronted with such new forms and shades that completely surpass in magnificence all that he "has ever be held in his own country". Such an overwhelming encounter with the immensity of nature makes it difficult if not impossible for Darwin to "express his feelings". ${ }^{8}$ As Darwin becomes exposed to these overwhelming variety of natural expressions, his naturalist mind struggles to make sense of unity in diversity. The motivations of the voyage of the Beagle embraced the two developments that forced the European mind to reconsider the dominant narratives regarding the history of the world. In fact, taxonomical efforts and imperial expansion, both present in the Beagle, revealed that the plant and animal kingdoms were incalculably larger and more elaborate than anyone had foreseen before. As Drayton" puts it, "empire brought home to Europe the shock of the world's diversity" and Darwin experienced this bewilderment in his own flesh at a young age. ${ }^{9}$

Taxonomy, the art of classification, seeks to group organisms on the basis of their shared characteristics. Sitting in the midst of the debate, Darwin anticipated the difficulties that continued to haunt biology. In a letter written to his friend Joseph Hooker he declared that "it is really laughable to see what different ideas are prominent in various naturalists' minds, when they speak of 'species"'. The degree of uncertainty of the term forced some naturalists to consider that resemblance was the most important variable in defining a species, while descent was of no avail. For others, as Darwin points out, "resemblance seems to go for nothing, and Creation the reigning idea". There were also some naturalists who believed that sterility was an abiding assessment for acknowledging a species while others discarded the test of sterility all together. Darwin's final conclusion on the species problem is categorical: "it all comes - he believes- from trying to define the indefinable".

Just like Darwin, Foucault ${ }^{10}$ tackles this frustrated attempt of defining the indefinable. He introduces the subject in the same manner as Darwin, pointing to the absurdity of the problem to the point that the way he does it produces laughter. But Foucault's laughter is not necessarily comical as is Darwin's; it is a laughter that shatters, a laughter that reveals a deep frustration towards our cognitive capacities. Foucault recalls his reading of a passage in Jorge Luis Borges' El idioma analitico de John Wilkins which threatened all the recognizable milestones of his thought, breaking up all the orderly planes and all the surfaces with which we are used to "tame the wild profusion of existing things". What Foucault read in the Argentinian writer was apparently so disturbing that it threatened, "with collapse our age-old distinction between the Same and the Other". This is precisely the problem of classification, the species problem. 
Borges' passage quotes a 'certain Chinese encyclopedia' in which it is written that animals are divided into:
A. belonging to the Emperor
B. embalmed
C. tame
D. suckling pigs
E. mermaids
F. fabulous
G. stray dogs
H. included in the present classification
I. frenzied
J. innumerable
K. drawn with a very fine camelhair brush
L. et cetera
M. having just broken the water pitcher
N. that from a long way off look like flies"11

Foucault concludes that in the stupefaction of this taxonomy, there is a clear piece of evidence that captures our mind in one single and abrupt leap. By ways of the allegory, the exotic appeal of an alternative scheme of thought manifests itself and at the same time indicates the profound limitation of our own: "the stark impossibility of thinking that" ${ }^{10}$ And why is it impossible to think that? Foucault's analysis points to the grid of identities, similitude's and analogies that allow a specific culture to establish the validity of a certain classification method with absolute certainty. This "table", as Foucault calls it, is built upon the repeated attempts of sorting out an endless array of different and similar things. From this effort a sort of coherence emerges that is neither determined by a necessary concatenation, nor inflicted on us by immediately visible contents. For taxonomy is not a matter of connecting consequences, but of assembling and separating, of examining, of matching particular contents: "There is nothing more tentative, nothing more empirical (superficially, at least) than the process of establishing an order among things; nothing that demands a sharper eye or a surer, better- articulated language; nothing that more insistently requires that one allow oneself to be carried along by the proliferation of qualities and forms" $" 10$

Darwin was well aware that there was no similitude and no distinction that was not the outcome of a detailed operation and of the application of a preliminary criterion. His groundbreaking argument for the transformation of species played out against a century-long debate around the nature of living species. These debates were philosophical in nature. The species problem demanded a 'system of elements' as Foucault states. That is a demarcation of the pieces by which the similarities and differences can be exposed, the kinds of deviation by which those pieces can be disturbed, and, lastly, the threshold above which there is a distinction and beneath which there is a similitude. All these elements are imperative for the establishment of even the simplest form of order. Should resemblance be the reigning idea for defining a species? What about descent? Is it not an infallible criterion? What happens with Creation? Does a divine design have to do with the definition of a species?

Darwin's reconnaissance of a wider world was a key element in his later thinking. In fact, as the world grew bigger and bigger through imperial expansion the tendency to establish a universal order of things became an irresistible intellectual endeavor. In this sense, Darwin owed a debt both to his botanical forerunners and to the glories of empire. The English naturalist did not only profit from the fruits of empire during his world voyage, he also benefitted from the enormous collections of specimens that were kept in European museums, cabinets and botanical gardens. Using Latour's concept of knowledge production and accumulation, we can argue that Darwin gained from the privileged position that England possessed as a center of collection and accumulation. Latour claims that these centers contributed significantly to the construction and dissemination of scientific knowledge. They have become inextricably linked to the rise of European science. Latour creates a model of the construction of scientific knowledge in order to describe the production and accumulation of "immutable and combinable mobiles" (recorded observations such as specimens, charts, maps), which are collected from the peripheries and returned to a center where they are combined and interpreted in many ways. This dynamic is crucial because it allows centers of calculation to act at a distance.

One example of the way centers of calculation became crucial for Darwin's thought and work is the role that the Royal Botanical Gardens at Kew played in the elaboration of his theory. In fact, Darwin maintained a very active connection with the son of William Hooker, director of Kew. Joseph Dalton Hooker, who would become director of the Botanical Gardens after his father's death in 1865 , became a very dear friend of Darwin a few years after he returned from his Beagle voyage. They had become acquainted in 1843 while Darwin looked for a good plant taxonomist to work on the specimens he had collected in his voyage. Hooker had at his disposal the world in a garden, as was the inspiration of botanical gardens. Paradise had once comprised all the fauna and flora of the earth. In an effort to recreate this space, botanical gardens were created in Europe and the Royal Botanical Gardens at Kew were the crowning of this effort. The gardens had become a central institution of both Victorian science and the British Empire. ${ }^{9}$

In fact, one of Darwin's most provocative letters was written to Hooker who would become one of his most important and loyal friends. This letter, written in 11 January 1844 arrived at Kew with a surprising message: "it is like confessing a murder", Darwin said, half jokingly, when expressing for the first time an idea that would redefine the world. ${ }^{3}$ Darwin was explaining to Hooker his suspicions that species were not fixed as created by God, but had come into being by a process that he would later call "natural selection". "You will now groan" said Darwin, apologizing to Hooker for his drastic statement, "and think to yourself "on what a man have I been wasting my time writing to"'. Kew's usefulness to Darwin was essential. These two men exchanged 1400 letters that account for around 10\% of Darwin's surviving correspondence. ${ }^{3}$ Not only did Darwin see in Hooker an innate classifier who could give his collections the meticulousness he needed ${ }^{12}$ but he also profited from the extensive network that the Botanical Garden provided him. Through networks like Kew, Darwin himself would finally become and act as a center of accumulation. In fact, he wrote letters to all parts of the world. His correspondence was one of the most important means by which he gathered information and discussed theories. Darwin maintained contacts in Britain and overseas with gardeners, diplomats, colonial officials and naturalists who provided him with annotations on the fauna, flora and peoples of the world. Darwin exchanged letters with nearly 2000 people during his lifetime.

In this article we have argued that a way to understand Darwin's revolution can be Kuhn's idea that theories are intellectual productions 
that are dependent on social contexts. We have followed Kuhn's insight that science is not essentially motivated by empirical discoveries but by mental constructs. We have developed three of these constructs: design, time and empire, as being in some sense accountable for permitting Darwin to ponder on the possibility of a paradigm shift. Thus, we will conclude this chapter with a methodological reflection about Darwin's historical record. In fact, Kuhn's concept of a paradigm forces us to broaden our sources of information in order to include the social context on which a scientific theory is born. What is a historical record? We can think of it as the sum of all the sources that provide us with appropriate information for our research. Where do we start if we want to reflect on Charles Darwin? The first element that comes into mind of course is Darwin's most important published work On the origin of species. This leads us to the general description of a broader category within Darwin's historical record; that is everything that Darwin published throughout his life. This type of historical record would seem to have the greatest amount of legitimacy since by the act of publication it is understood that a series of steps of edition, correction and general improvement of the original work have been performed. Editorial conditions and peer reviews are somehow put in place to secure that what is finally published and made public is the purest and most acceptable dimension of what the author wanted to say. Is this enough information to reconstruct a historical record? In fact, this necessary process that published works go through also leads to a series of silences. The scientist's discourse in its search for clearness and authority does not give an account of many elements of negotiation and asymmetrical power relations that are generally not at all present in such sterile manifestations.

These ideas lead us to a second historical source that is available to historians of science and that is Darwin's immense correspondence. Darwin's correspondence provides us with an invaluable source of information about his own intellectual development and social network, information that is not always manifest in his published works. It is also an excellent source to understand how postcolonial science works. As we mentioned earlier, his intensive correspondence was one of the most important means by which he gathered data and discussed ideas. The letters provide a picture of the development of his thinking, shedding light on his formative years and the years of his voyage around the world. The letters also chronicle the period that led up to the publication of his controversial theory of 'natural selection' and the heated debates that followed. In the 1860s and 1870 s, Darwin was, additionally, busy with botanical investigations: studying adaptations in orchids, different types of sexual reproduction in other plants, the origin of climbing plants, and the physiology of insectivorous plants. The letters illustrate how this work, and his studies of human descent, sexual selection, and the expression of emotions, all contributed to the refinement of the theory presented in On the origin. But the letters also show how many research initiatives in which Darwin invested a great deal of time, led only to frustrations and dead ends. These circumstances that apparently have no scientific transcendence are especially interesting for the history of science that should not focus exclusively on the success stories since all the inbetweens have enormous analytical potential.

Following this second dimension of Darwin's historical record, that is his correspondence, allows the historian to echo the need to build global science stories that do not miss the wealth of contextual and local insights. This concern for the global aspect of science, for the importance of travel in the making of scientific knowledge, for the asymmetrical relations in scientific networks and the various complexities and fluidity of these relations of power could be overlooked if we were to limit ourselves only to the printed books we discussed earlier. If we include this transatlantic correspondence into our historiographical record, we will be able to conceptualize an alternative model that accounts for science as a mobile and communicative activity dependent on long distance networks. These sources make visible the connections and entanglements of local histories in a global dynamic. ${ }^{13-15}$

\section{Funding}

There was no funding provided.

\section{Acknowledgments}

None.

\section{Conflict of interest}

Author declares that there is no conflict of interest.

\section{References}

1. Kuhn T. The structure of scientific revolutions. Chicago: University of Chicago Press; 1962.

2. Darwin C. Journal of researches into the geology and natural history of the various countries visited by H.M.S. Beagle. London: Henry Colburn; 1839.

3. Darwin C. Darwin to Henslow. Darwin Correspondence Project. Letter no. 204,1833 .

4. Darwin C. The Origin of Species by Means of Natural Selection, or the Preservation of Favoured Races in the Struggle for Life. London: John Murray, Albemarle Street; 1859.

5. Lustig JA. Darwin's Difficulties. The Cambridge Companion to the "Origin of Species". In: M Ruse, JR Richards, editors. New York: Cambridge University Press; 2008.

6. Darwin C. The Autobiography of Charles Darwin 1809-1882. With original omissions restored. New York; 1958.

7. Darwin C. Darwin CR to Lubbock, John. Darwin Correspondence Project. University of Cambridge. 1859;7:388.

8. Darwin C. Journal of researches into the natural history and geology of the countries visited during the voyage of H.M.S. Beagle round the world, under the Command of Capt. Fitz Roy. London: John Murray; 1845.

9. Drayton R. Nature's Government: Science, Imperial Britain, and the "Improvement" of the World. New Haven: Yale University Press; 2000.

10. Foucault M. The order of things. Archaeology of the Human Sciences. New York: Pantheon books; 1970.

11. Borges JL. El idioma analítico de John Wilkins. Otras inquisiciones. Buenos Aires, Sur; 1952.

12. Townshend E. Kew's connection with Charles Darwin: an evolutionary relationship. Kew magazine. 2009.

13. Subrahmanyam S. Connected Histories: Notes towards a Reconfiguration of Early Modern Eurasia. Modern Asian Studies. 1997;31(3):735-762.

14. Mayr E. Species Concepts and Definitions. The Species Problem. Washington: American Assoc. for the Advancement of Science; 1957.

15. Sevilla A, E Sevilla. Inserción y participación en las redes globales de producción de conocimiento: el caso del Ecuador del siglo XIX. Historia Crítica 50(Mayo-Agosto). 2013;79-103. 